\title{
Implementasi MSIP (Manajemen Sistem Informasi Pendistribusian) Keluar Masuk Obat Pada Gudang Farmasi Kelapa
}

\author{
Sarwindah, Marini, Tirta Aditya Pratama \\ Program Studi Sistem Informasi, STMIK Atma Luhur, Bangka Belitung, Indonesia \\ e-mail: 1indah_syifa@atmaluhur.ac.id, 2arinimarini44@atmaluhur.ac.id, ${ }^{3}$ Tirta.AP@gmail.com
}

\begin{abstract}
Abstrak-Proses pendistribusian obat merupakan salah satu proses utama dalam pengelolaan obat yang memiliki peran penting dalam mengelola ketersediaan obat. Dalam pelaksanaannya, proses pendistribusian obat membutuhkan informasi mengenai penerimaan, persediaan, dan pengeluaran obat antara pihak pengirim dan pihak penerima, dimana informasi tersebut dapat dirubah secara berkala sesuai dengan masuk dan keluarnya obat. Oleh karena itu Gudang Farmasi di Puskesmas Kelapa yang memiliki tugas untuk melakukan pendistribusian obat ke sub unit pelayanan sebaiknya dapat memenuhi kebutuhan dalam mengelola informasi pada proses pendistribusian obat. Penelitian ini dilakukan untuk menganalisis dan merancang "Sistem Informasi Distribusi Obat Pada Gudang Farmasi Kelapa Berbasis Web". Dalam penelitian ini, Metode penelitian yang digunakan penulis ialah metode Objek Oriented dengan studi kasus pada bagian distribusi obat dan untuk merancang sistem informasi menggunakan pendekatan objek Oriented dan untuk metode pengembangan menggunakan metode UML. dapat di ketahui bahwa Sistem Informasi Distribusi Obat Pada Gudang Farmasi Kelapa Berbasis Web saat ini masih mengalami kendala, dikarnakan ada beberapa proses pengolahan data yang masih bersifat konvensional, dan masih belum terintegrasinya data-data persediaan obat dengan data-data penjualan obat dan lain sebagainya.
\end{abstract}

Kata Kunci: Optimalisasi, Sistem Informasi dan Pendistribusian.

\begin{abstract}
The process of drug distribution is one of the main processes in drug management which has an important role in managing drug availability. In its implementation, the drug distribution process requires information regarding the receipt, supply and expenditure of the drug between the sending and receiving parties, where the information can be changed periodically according to the entry and exit of the drug. Therefore Pharmacy Pharmacy warehouse in Kelapa Puskesmas which has the task of distributing drugs to sub-service units should be able to meet the needs in managing information on the drug distribution process. This research was conducted to analyze and design "Web-Based Drug Distribution Information System in Coconut Pharmacy Warehouse". In this research, the research method used by the author is the Oriented Object method with case studies in the distribution of drugs and to design information systems using the Oriented object approach and for the development method using the UML method.it can be seen that the Drug Distribution Information System in the Web-Based Coconut Pharmacy Warehouse is currently experiencing problems, because there are some data processing processes that are still conventional in nature, and there is still no integration of drug inventory data with drug sales data and so forth
\end{abstract}

Keywords: Optimization, Information Systems and Distribution.

\section{PENDAHULUAN}

Pendistribusian obat merupakan salah satu proses utama dalam pengelolaan obat yang memiliki peran penting dalam mengelola ketersediaan obat. Dalam pelaksanaannya, proses pendistribusian obat membutuhkan informasi mengenai penerimaan, persediaan, dan pengeluaran obat antara pihak pengirim dan pihak penerima, dimana informasi tersebut dapat dirubah secara berkala sesuai dengan masuk dan keluarnya obat. Pembangunan sarana distribusi persedian farmasi sebagai salah satu upaya pembangunan yang di arahkan guna mencapai terpenuhinya kebutuhan persediaan farmasi bagi masyarakat .Untuk mencapai tujuan tersebut diperlukan sumber daya manusia di bidang kesehatan. Dengan berkembangnya teknologi informasi yang semakin ketat, maka suatu instansi membutuhkan suatu sistem informasi yang terkomputerisasi dalam menjalankan setiap kegiatannya. Hal ini disebabkan karena suatu sistem yang sudah terkomputerisasi mempunyai banyak kelebihan di bandingkan dengan sistem manual, agar permasalahan yang dihadapi teratasi dibutuhkan, maka perancangan sistem informasi pelayanan berbasis web agar permasalahan yang ada dapat di atasi. Hal ini yang mendorong agar pekerjaan menjadi lebih cepat, penyimpanan data lebih aman, dan pencarian data obat lebih cepat tidak membutuhkan waktu yang lama.Dalam penelitian ini digunakan metode pengembangan perangkat lunak waterfall. Metode PAST memiliki beberapa tahapan pengembangan yaitu Tahapan Pengumpulan data Analisa Kebutuhan Sistem, Tahapan Perancangan Sistem, Tahapan Desain Sistem, dan Tahapan Implementasi Sistem. Tujuan dari penelitian ini adalah terciptanya sebuah system yang sudah terkomputerisasi berbasis web dalam melakukan pengecekan dan pencarian data obat berbasis komputer. Penetian pendukung dari hasil penetian yang telah ada sebelumnya yang berkiatan dengan penetian tersebut.

Dari penelitian Isna Sugih Hartini dan Marchaban (2016) dari jurnalnya yang berjudul "Evaluasi Pelaksanaan Cara Distribusi Obat Yang Baik (CDOB) pada Apotek di Kecamatan Mlati kabuupaten Sleman Yogyakarta "Penelitian ini merupakan penelitian deskriptif kualitatif yang dilakukan terhadap apotek dengan mengkaji gambaran penerapan $\mathrm{CDOB}$ pada aspek profil sarana, bangunan dan peralatan, pengadaan, penerimaan dan penyimpanan, penyaluran, penanganan produk kembali dan kadaluarsa, pemusnahan, dan lain-lain.

Dari penelitian Jimbrif T. Lumenta (2015) dari jurnalnya yang berjudul "Evaluasi Penyimpanan Dan Distribusi Obat Psikotropika Di Rumah Sakit Jiwa Prof. Dr. V. L. Ratumbuysang Manado" Penelitian ini 
bertujuan untuk mengevaluasi penyimpanan dan distribusi obat psikotropika di RSJ Prof. Dr. V. L. Ratumbuysang menggunakan metode deskriptif kualitatif dengan pendekatan retrospektif dan prospektif. Hasil penelitian menunjukan bahwa sistem penyimpanan obat psikotropika di RSJ Prof. Dr. V. L. Ratumbuysang secara keseluruhan belum sesuai dengan Standar Penyimpanan berdasarkan Pedoman Pengelolaan Perbekalan Farmasi.

Sedangkan dari penelitian Diah Puspitasari (2017) dari jurnalnya yang berjudul "Sistem Informasi Persediaan Obat Berbasis Web Pada Klinik Dan Apotek Hermantoni Karawang" dibutuhkan suatu perencanaan persediaan obat di Klinik Hermantoni yang dapat menentukan besarnya persediaan dalam meng-cover seluruh permintaan dan juga sebuah sistem informasi yang dapat mendukung segala aktivitas mengenai manajemen persediaan obat.

\section{METODE PENELITIAN}

Dalam penelitian ini untuk mencapai tujuannya digunakan beberapa metode penelitian yang mendukung yaitu:

\subsection{Model Pengembangan FAST}

Model pengembangan Fast merupakan model pengembangan sistem secara berurutan yaitu melalui tahapan penyelidikan awal, analisis masalah, analisis kebutuhan, desain logis, analisis keputusan, konstuksi, pelaksanaan, operasi dan tahap dukungan. Dalam penelitian ini penulis menggunakan sub tahapan analisa sistem dan desain sistem.

\subsection{Metode Object Oriented $(O O)$}

Metode berorientasi objek dimana didalam metode ini terdapat class object, method, dan atribut yang berkaitan dengan sistem informasi yang akan dibuat pada gudang farmasi puskesmas kelapa.

\subsection{Metode Fungsional Atau Struktur Data}

Metode struktur data atau fungsional adalah metode data yang terstruktur dan segala sesuatunya berdasarkan dokumen yang mengalir.

Dalam pengumpulan data dan informasi untuk melakukan analisa dengan Kerangka kerja dibawah ini:

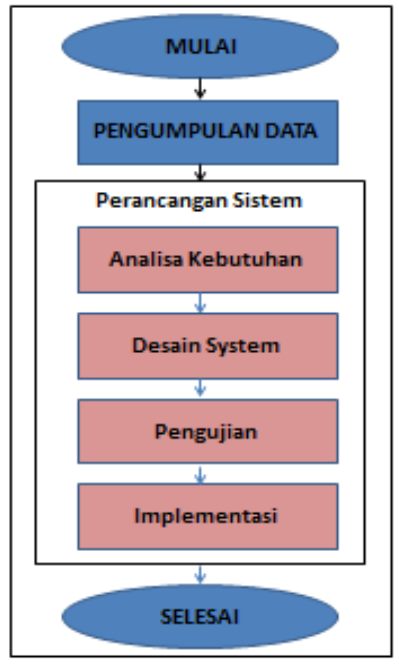

Gambar 1. Kerangka Kerja Penelitian

\subsection{Tools}

Alat bantu yang digunakan Unifed (UML) yang berdiri dari beberapa tahap diagram dan komponen guna membantu dalam menganalisa dan merancang sistem yaitu: Activity Diagram, Use Case Diagram, Squeence Diagram, Entity Relationship Diagram(ERD).

\section{HASIL DAN PEMBAHASAN}

\subsection{Proses Bisnis}

Proses dari Gudang Farmasi Puskesmas Kelapa yang sedang berjalan dilihat dalam dokumen. Apapun uraian prosedur atau proses bisnis sebagai berikut:

a. Proses Permintaan obat 


\section{JURNAL MEDIA INFORMATIKA BUDIDARMA}

Volume 4, Nomor 2, April 2020, Page 332-339

ISSN 2614-5278 (media cetak), ISSN 2548-8368 (media online)

Available Online at https://ejurnal.stmik-budidarma.ac.id/index.php/mib

DOI 10.30865/mib.v4i2.1952

Apoteker meminta obat pada bagian gudang, lalu petugas gudang mengecek obat apakah masih tersedia atau tidak tersedia. Jika obat tidak tersedia maka bagian gudang konfirmasi kekepala puskesma dan kepala puskesmas terima konfirmasi. Jika obat tersedia bagian gudang serahkan obat ke apoteker lalu apoteker terima obat.

b. Proses Pemesanan Obat

Bagian gudang cek data obat lalu bagian gudang buat LPLPO yang berisikan isi pemesanan obat lalu petugas gudang serahkan LPLPO lalu Supplier terima LPLPO pemesanan obat.

c. Proses Penerimaan Obat dan Faktur

Supplier serahkan obat beserta faktur dan bagian gudang terima obat dan faktur lalu petugas gudang cek obat dan faktur sesuai atau tidak sesuai.Jika tidak sesuai bagian gudang tandai obat yang tidak sesuai lalu bagian gudang kembalikan obat lalu supplier terima obat dang anti obat lalu supplier gantikan obat baru lalu bagian gudang terima obat baru lalu catat di buku stok lalu bagian obat simpan obat di gudang.

d. Proses Pembuatan Laporan

Bagian gudang buat laporan persediaan obat lalu serahkan laporan persediaan obat kekepala Puskesmas lalu Kepala Puskesmas terima laporan persediaan obat.

\subsection{Activity Diagram}

1. Activity Diagram Proses Permintaan Obat

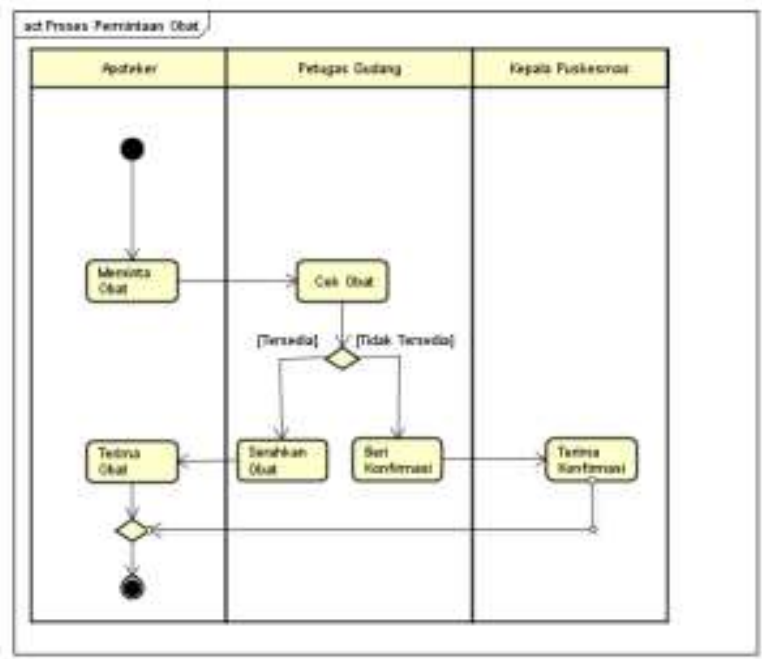

Gambar 2. Activity Diagram Proses Permintaan Obat

Apoteker meminta obat pada bagian gudang, lalu petugas gudang mengecek obat apakah masih tersedia atau tidak tersedia. Jika obat tidak tersedia maka bagian gudang konfirmasi kekepala puskesma dan kepala puskesmas terima konfirmasi. Jika obat tersedia bagian gudang serahkan obat ke apoteker lalu apoteker terima obat.

\section{Activity Diagram Proses Pemesanan Obat}

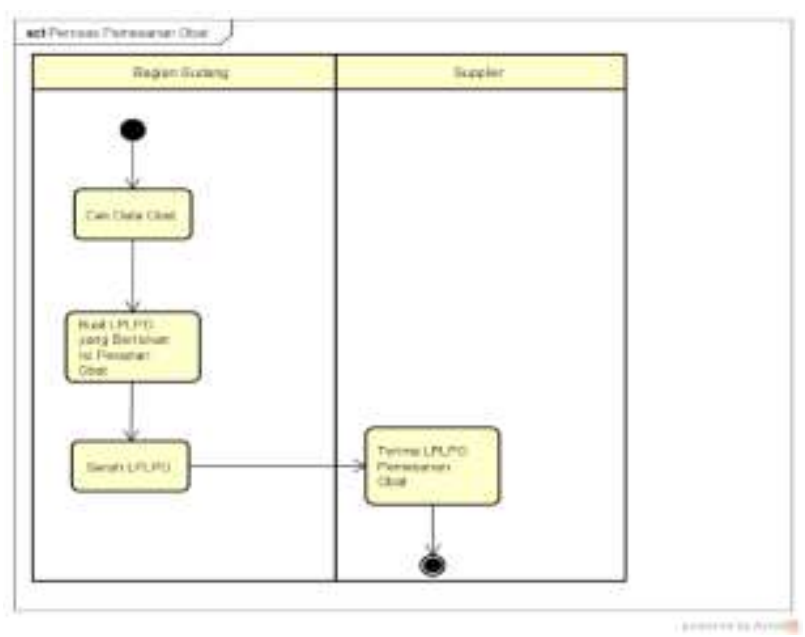

Gambar 3. Activity Diagram Proses Pemesanan Obat 
JURNAL MEDIA INFORMATIKA BUDIDARMA

Volume 4, Nomor 2, April 2020, Page 332-339

ISSN 2614-5278 (media cetak), ISSN 2548-8368 (media online)

Available Online at https://ejurnal.stmik-budidarma.ac.id/index.php/mib DOI 10.30865/mib.v4i2.1952

Bagian gudang cek data obat lalu bagian gudang buat LPLPO yang berisikan isi pemesanan obat lalu petugas gudang serahkan LPLPO lalu Supplier terima LPLPO pemesanan obat.

3. Activity Diagram Proses Penerimaan Obat dan Faktur

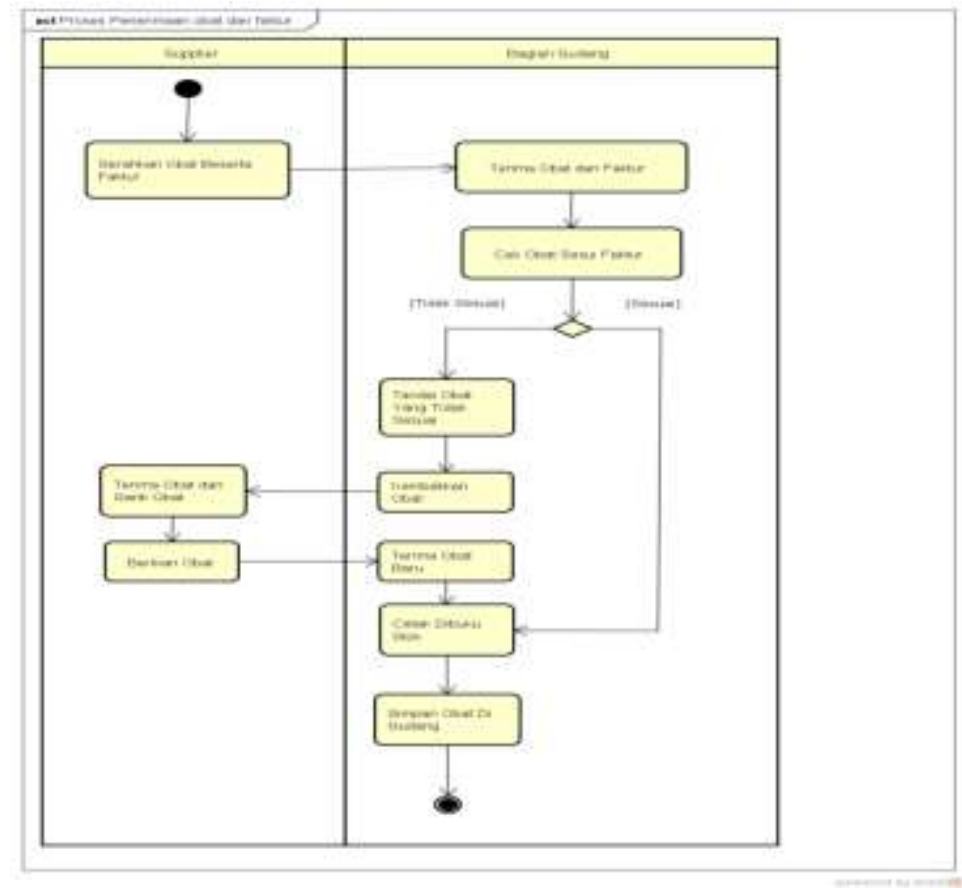

Gambar 4. Activity Diagram Proses Penerimaan Obat

Supplier serahkan obat beserta faktur dan bagian gudang terima obat dan faktur lalu petugas gudang cek obat dan faktur sesuai atau tidak sesuai.Jika tidak sesuai bagian gudang tandai obat yang tidak sesuai lalu bagian gudang kembalikan obat lalu supplier terima obat dang anti obat lalu supplier gantikan obat baru lalu bagian gudang terima obat baru lalu catat di buku stok lalu bagian obat simpan obat di gudang.

4. Activity Diagram Proses Pembuatan Laporan

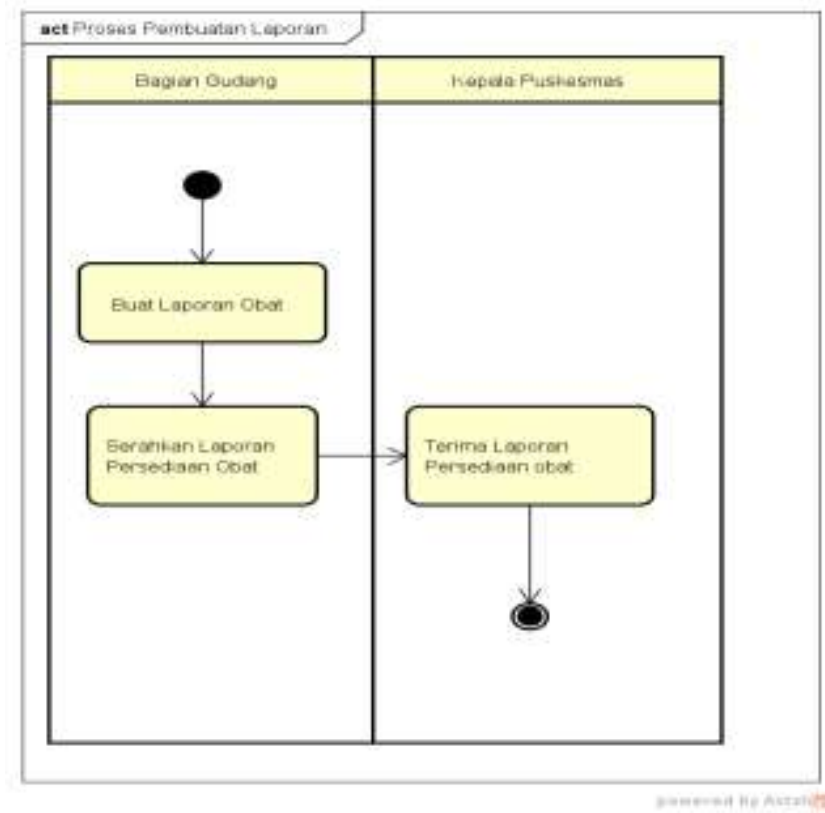

Gambar 5. Activity Diagram Proses Pembuatan Laporan

Bagian gudang buat laporan persediaan obat lalu serahkan laporan persediaan obat kekepala Puskesmas lalu Kepala Puskesmas terima laporan persediaan obat.

\subsection{ERD (Entity Relationship Diagram)}

Sarwindah, Copyright (C2020, MIB, Page 335 
JURNAL MEDIA INFORMATIKA BUDIDARMA

Volume 4, Nomor 2, April 2020, Page 332-339

ISSN 2614-5278 (media cetak), ISSN 2548-8368 (media online)

Available Online at https://ejurnal.stmik-budidarma.ac.id/index.php/mib DOI 10.30865/mib.v4i2.1952

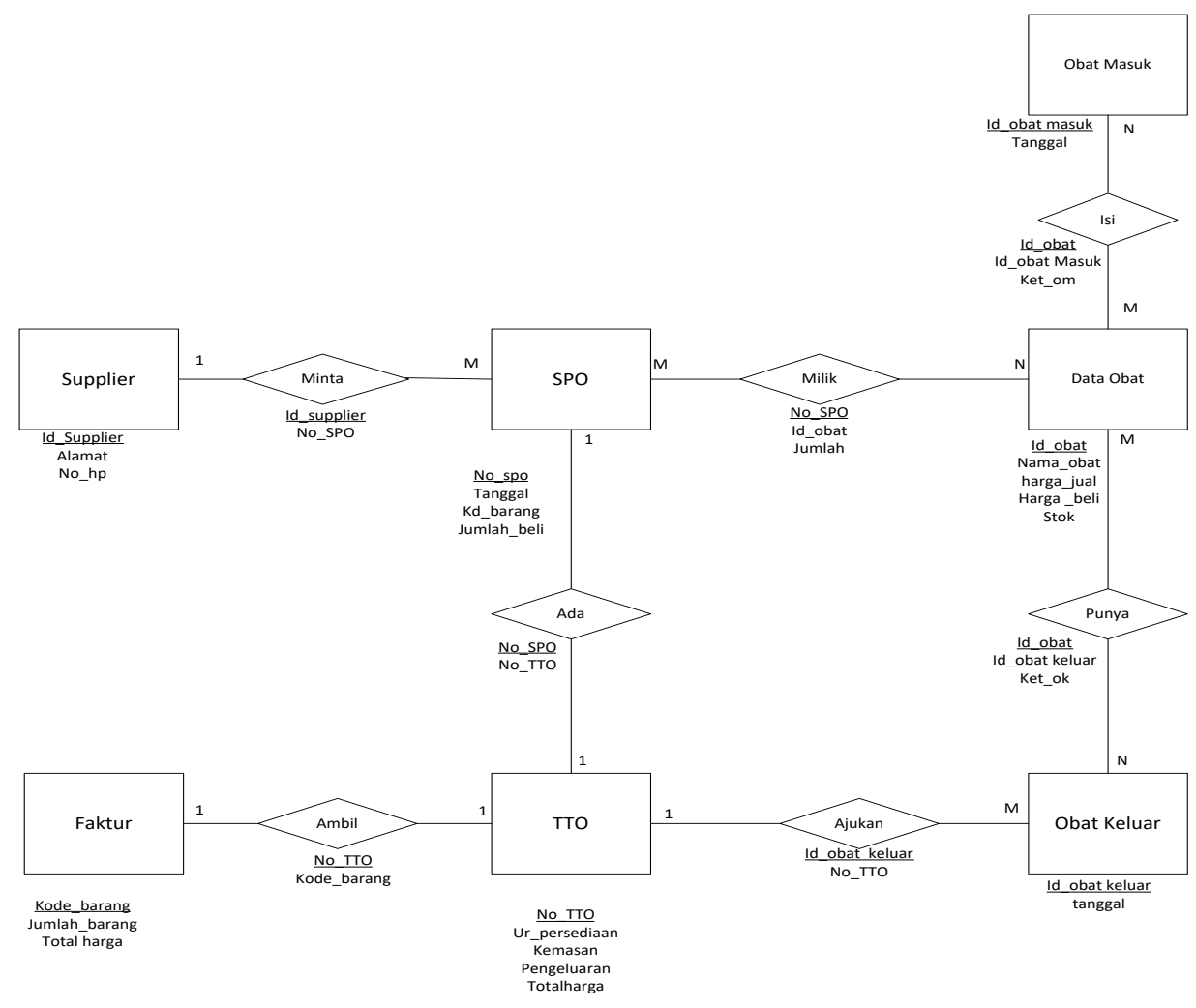

Gambar 6. Entity Relationship Diagram (ERD)

\subsection{Implementasi}

Berikut hasil dari sistem informasi distribusi obat.

1. Rancangan Layar Login

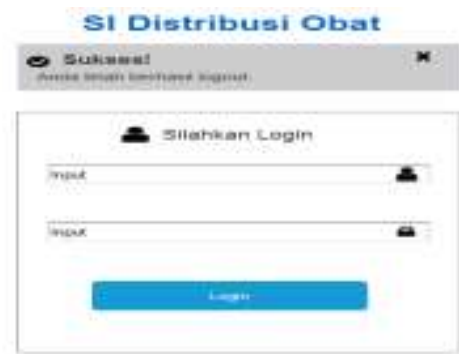

Gambar 7. Rancangan Layar Login

2. Rancangan Input Data Obat

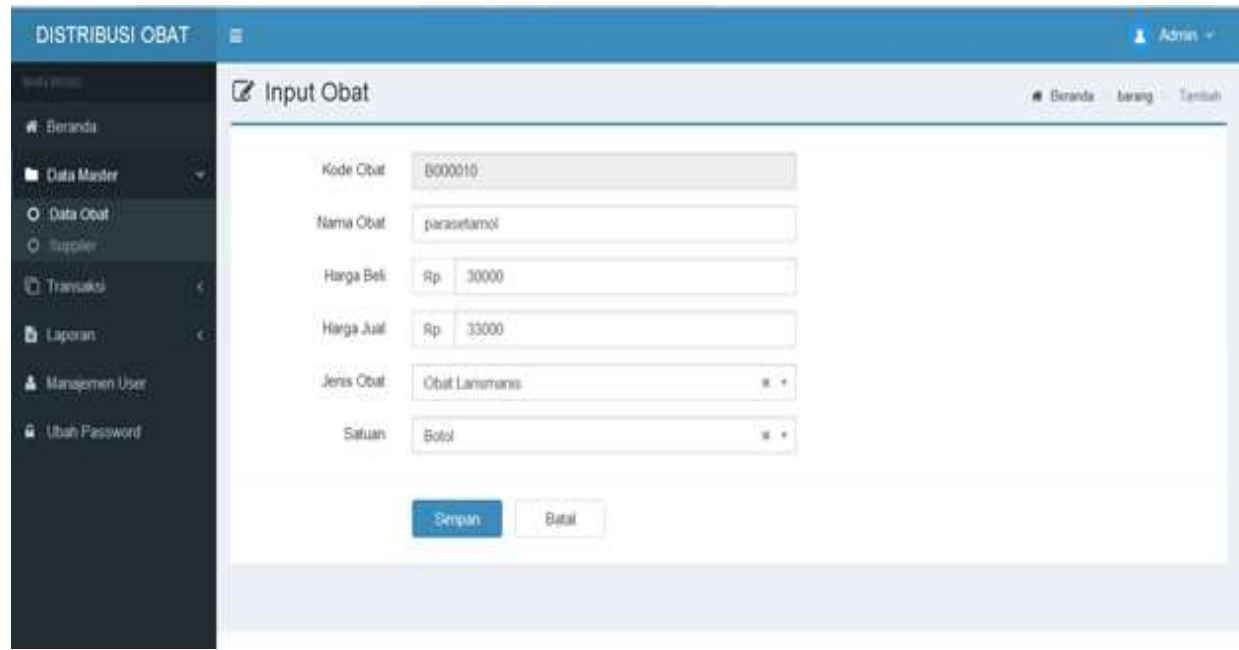

Gambar 8. Rancangan Layar Input Data Obat

Sarwindah, Copyright (C2020, MIB, Page 336 
JURNAL MEDIA INFORMATIKA BUDIDARMA

Volume 4, Nomor 2, April 2020, Page 332-339

ISSN 2614-5278 (media cetak), ISSN 2548-8368 (media online)

Available Online at https://ejurnal.stmik-budidarma.ac.id/index.php/mib DOI $10.30865 /$ mib.v4i2.1952

3. Rancangan Data Obat Setelah di Input

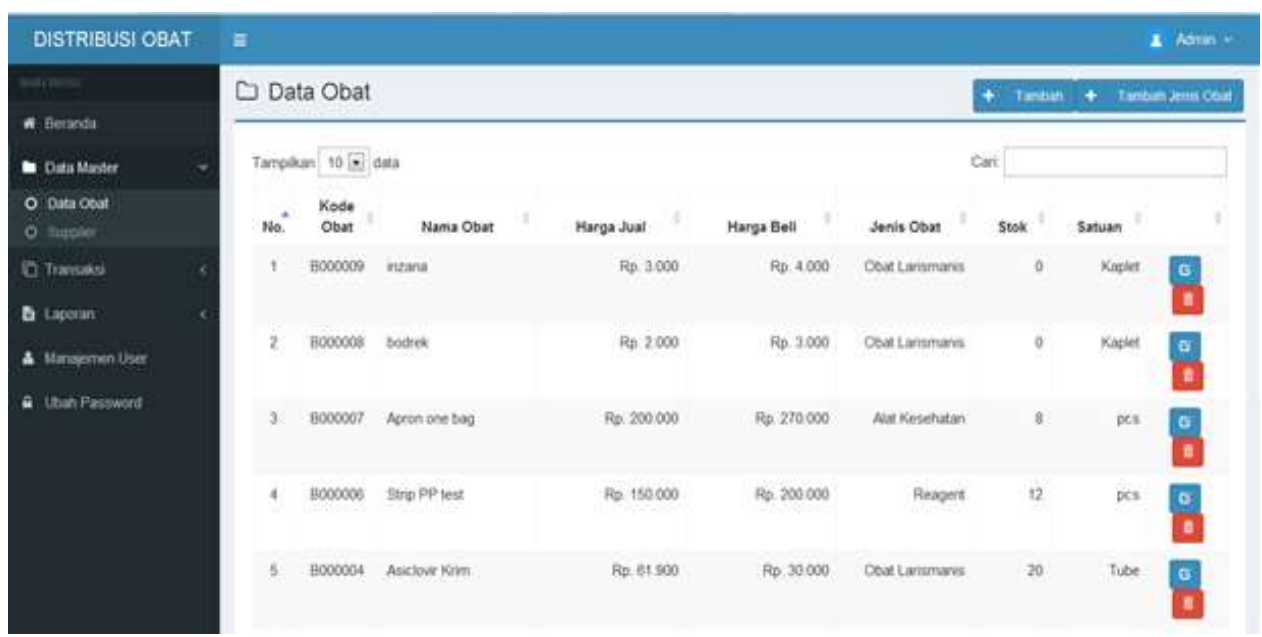

Gambar 9. Rancangan Layar Setelah di Input Data Obat

4. Rancangan Layar Entry Data Obat Masuk

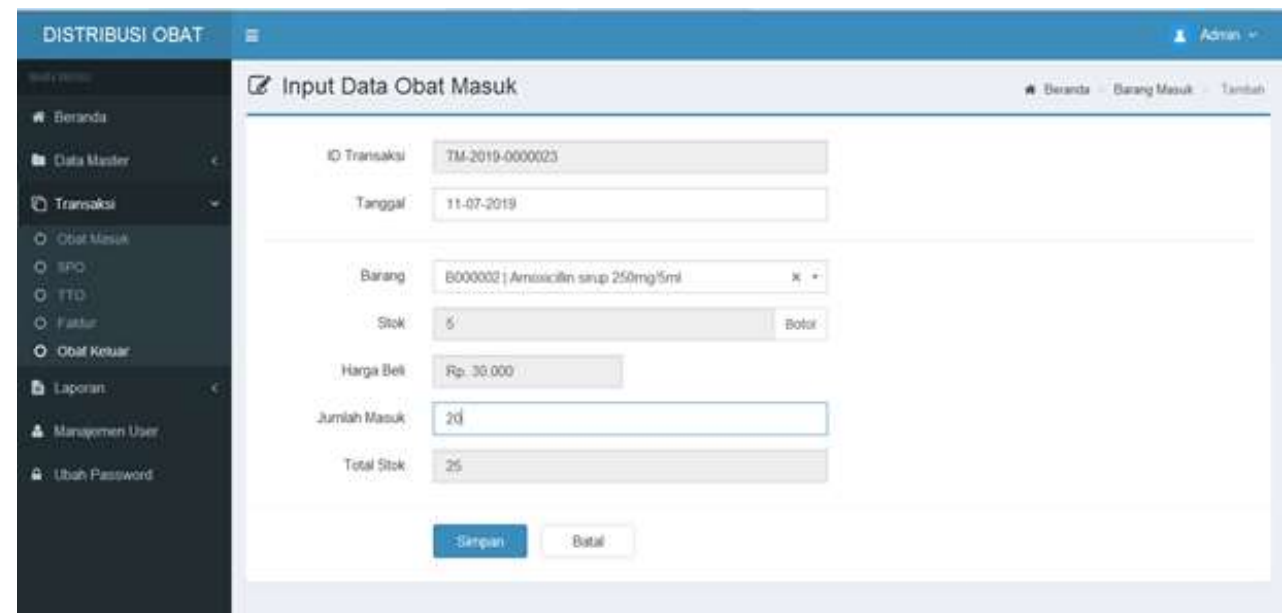

Gambar 10. Entry Data Obat Masuk

5. Rancangan layar Data Obat Masuk

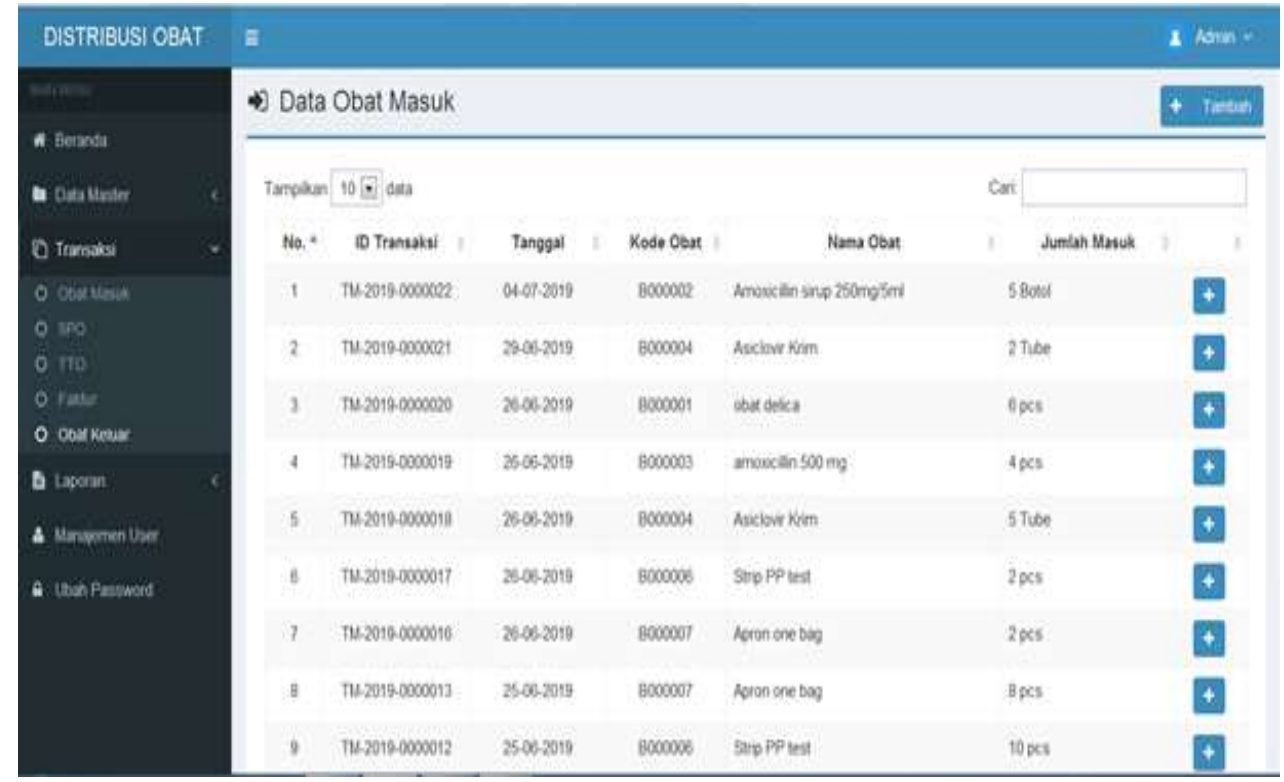

Gambar 11. Data Obat Masuk 
JURNAL MEDIA INFORMATIKA BUDIDARMA

Volume 4, Nomor 2, April 2020, Page 332-339

ISSN 2614-5278 (media cetak), ISSN 2548-8368 (media online)

Available Online at https://ejurnal.stmik-budidarma.ac.id/index.php/mib DOI $10.30865 /$ mib.v4i2.1952

6. Rancangan Data Pemesanan Obat

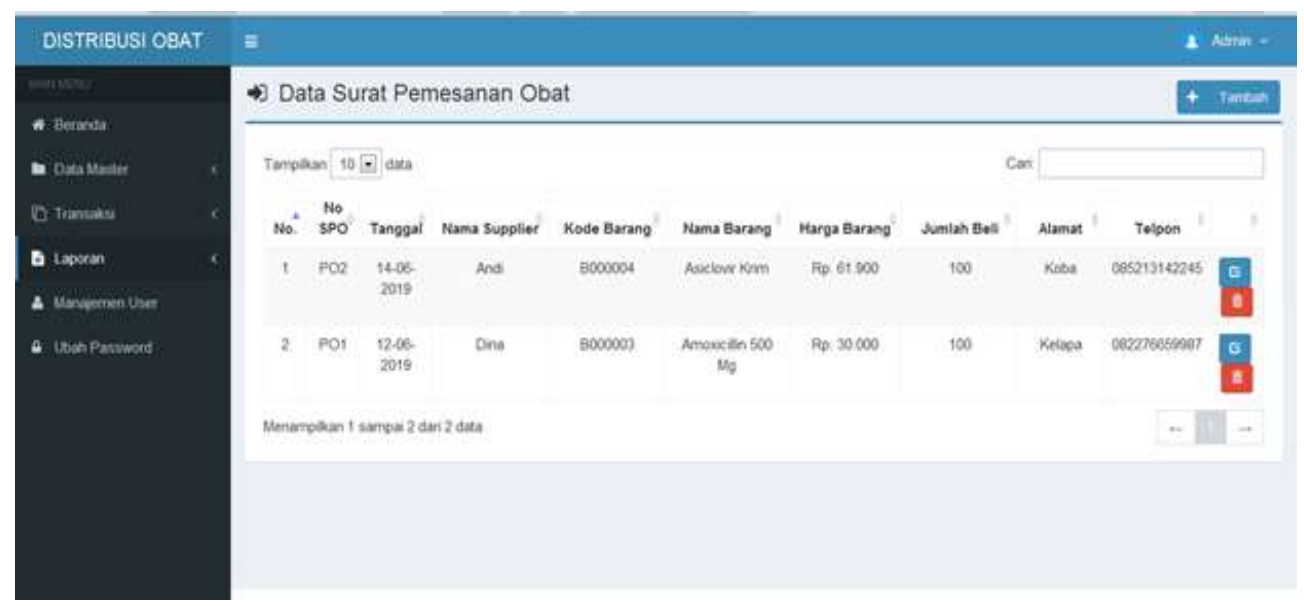

Gambar 12. Data Pemesanan Obat

7. Rancanagan Layar Entry Data Obat Keluar

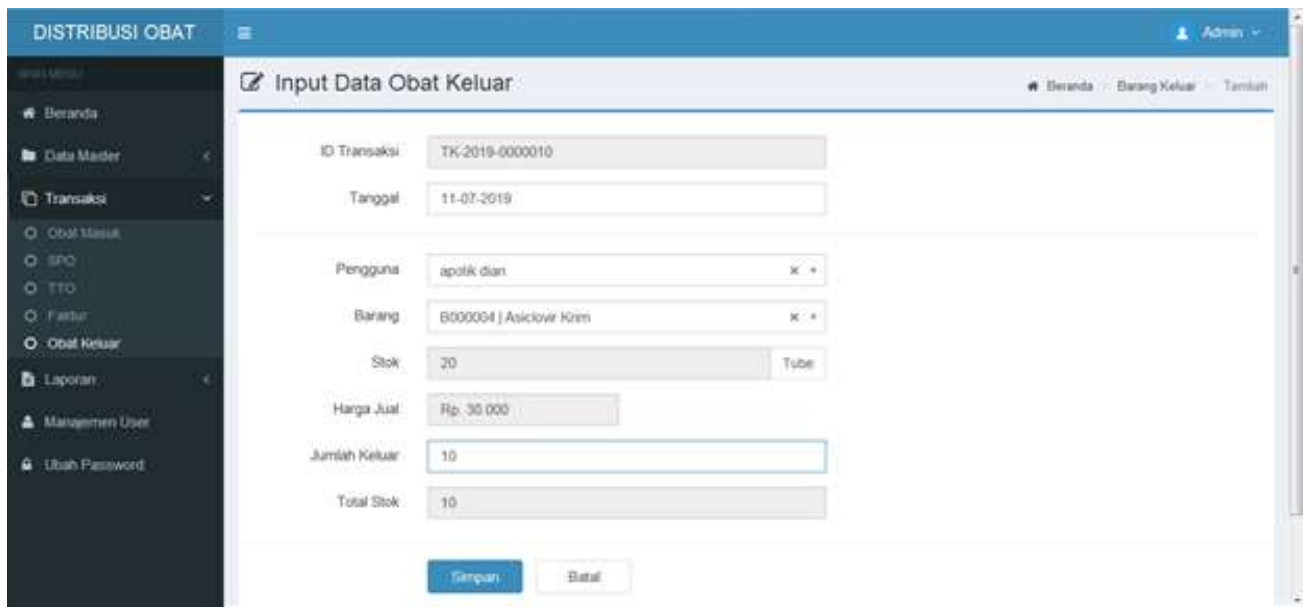

Gambar 13. Data Obat Keluar

8. Rancangan Layar Data Obat Keluar

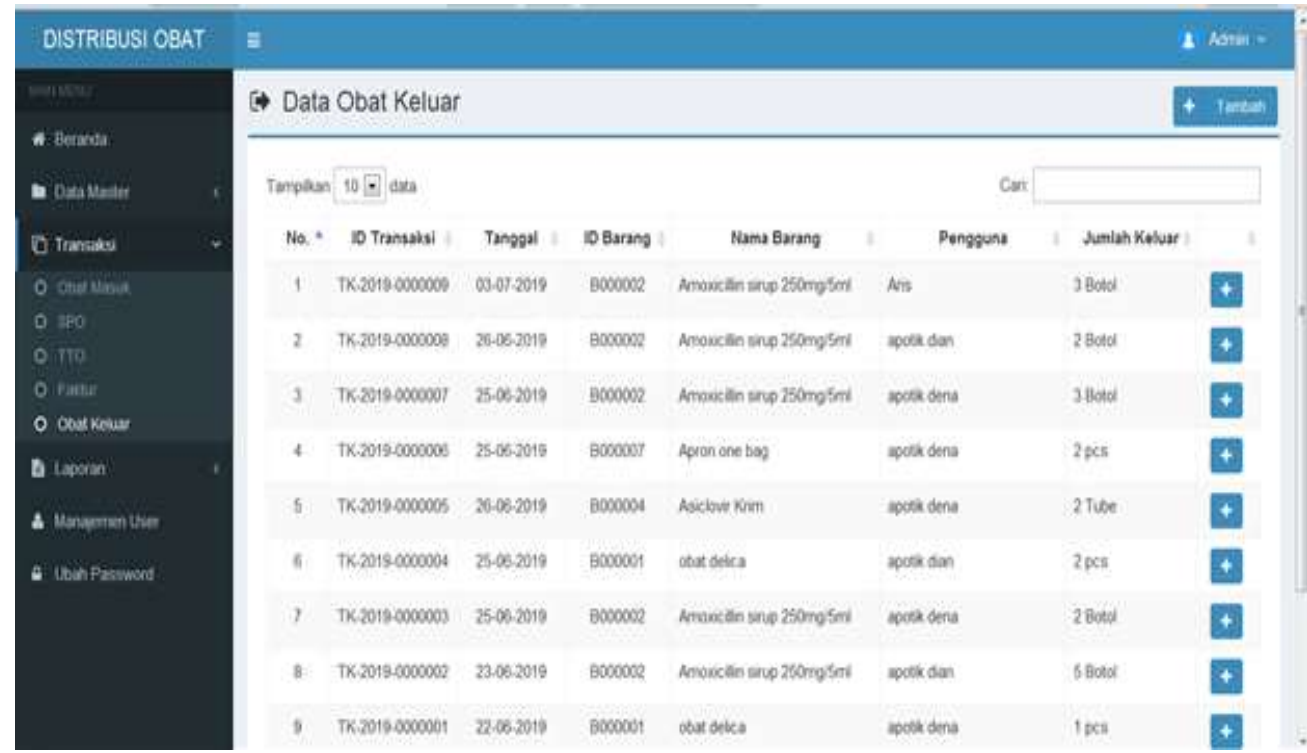

Gambar 14. Laporan Pemesanan Obat 


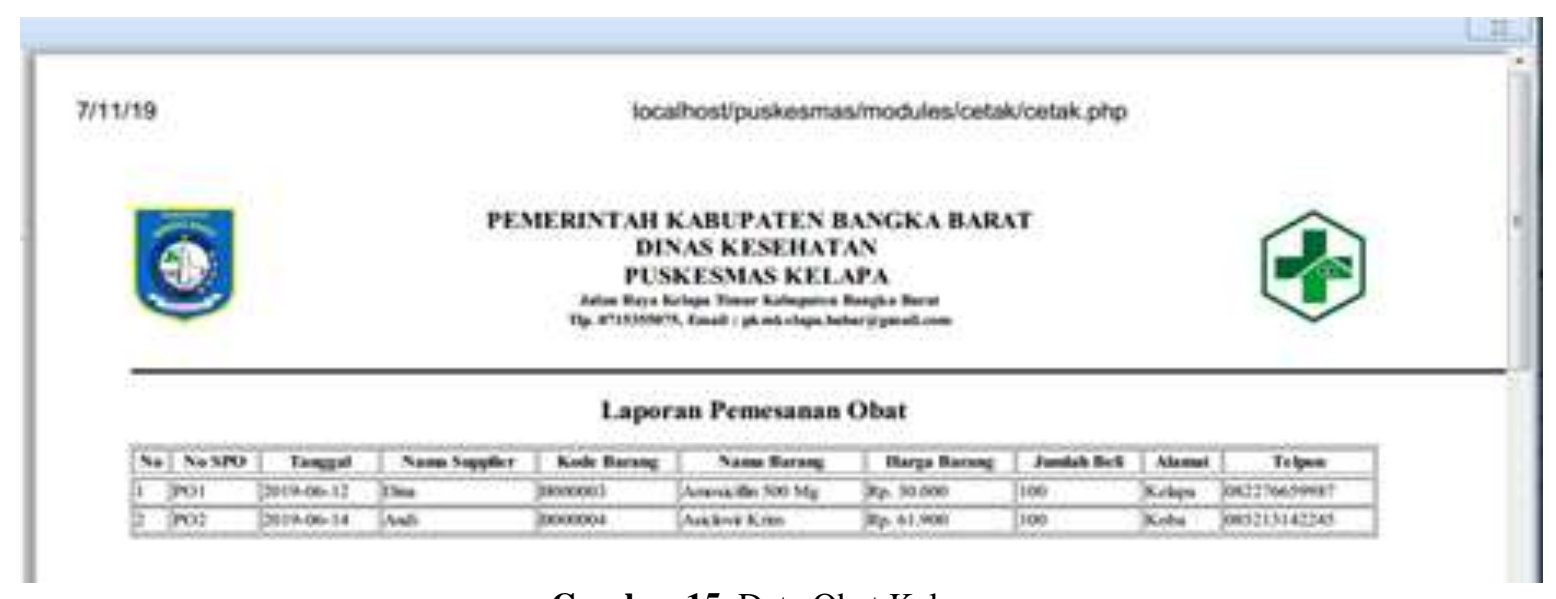

Gambar 15. Data Obat Keluar

\section{KESIMPULAN}

Berdasarkan analisa yang telah dilakukan dapat disimpulkan bahwa dengan adanya sistem pendistribusian obat puskesmas berbasis web ini dapat memudahkan mengetahui keluararan dan masuk obat serta penerimaan obat secara otomatis, Serta bisa mengetahui langsung laporan persediaan obat dan pemesanan obat , Karena informasi yang disajikan ini pada dasarnya berasal dari data masukan (input), maka sebelum memasukkan data harus di lakukan pengecekan terhadap kebenaran informasi yang dihasilkan sesuai yang diinginkan dan mempersiapkan dukungan hardware dan software yang spesifikasinya dapat mendukung sistem ini dengan baik dalam melakukan back-up data untuk mengantisipasi agar tidak terjadi hal-hal yang tidak kita inginkan.

\section{REFERENCES}

[1] Angeline Nasution, T. B., 2016. Sistem Informasi Penjualan Obat Berbasis Web Pada Apotek Perwira Jaya Bekasi. Informatics For Educators And Profesionals, 1(1), pp. 70-83.

[2] Hartini I. S., 2014. Evaluasi Pelaksanaan Cara Distribusi Obat Yang Baik Pada Apotek Di Kecamatan Mlati Kabupaten Sleman Yogyakarta.Yogyakarta.

[3] Yulianti Sinen, Widya Astuti, Hamidah Sri Supriati, 2017. Evaluasi penyimpanan dan pendistribusian obat di pt. Unggul jaya cipta usaha manado, pp.137-146.

[4] Diah Puspitasari, 2017. Sistem Informasi Persediaan Obat Berbasis Web Pada Klinik Dan Apotek Hermantoni Karawang. Jurnal Bianglala Informatika, 5(1), pp. 1-7.

[5] Muhammad faiz satrianegara, Emmi Bujawati, Guswani, 2018. Analisis pengelolaan manajemen logistik obat Di instalasi farmasi RSUD lanto daeng Pasewang kabupaten jeneponto, 10 (1) pp.37-47.

[6] Indrayani, Evi, Humdiana. Sistem Informasi Manajemen. Jakarta : Graha Ilmu., 2009

[7] Sarwindah, 2016. Sistem Informasi Manajemen Pemesanan Buku pada TOKO BUKU NURIS, Jurnal TEKNOSI, 2(2), pp. 77-84.

[8] Malinggas, Novianne E. R, dkk. (2015). Analisis Manajemen Logistik Obat di Instalasi Farmasi Rumah Sakit Umum Daerah DR Sam Ratulangi Tondano. Jurnal JIKMU.5:448-460.

[9] Sutabri, Tata. Sistem Informasi Manajemen. Yogyakarta : Andi., 2008

[10] Helisa, Bahar, 2016. Sistem Informasi Distribusi Obat Puskesmas Pada Gudang Farmasi Berbasis Web. JUTISI, 5(2), pp. 1047-1056.

[11] Maria Oktaviani, Desi Candrika, 2018. Aplikasi System Manajemen Task Penilaian Kerja(KPI)pada PT Intisoft Mitra Sejahtera 10(3) pp. 306-314

[12] Badaruddin,M (2015), Gambaran Pengelolaan Persediaan Obat Di Gudang Farmasi Rumah Sakit Umum Daerah Kota Sekayu Kabupaten Musi Banyuasin Palembang Tahun 2015, Universitas Islam Negeri Syarif Hidayatullah, Jakarta.

[13] Indrajani, S.Kom, MM. Perancangan Basis Data. Jakarta : Elex Media Komputindo., 2011

[14] Tri Utami, Bambang Eka Purnama, 2015. Pembangunan Sistem Informasi Penjualan Obat Pada Apotek Punung. IJNS - Indonesian Journal on Networking and Security, 4(2), pp. 44-49.

[15] Liwu, I. 2017. Analisis Distribusi Obat pada Pasien Badan Penyelenggara Jaminan Sosial (BPJS) di RSUP Prof. Dr. R.D Kandou Manado. Jurnal Biomedik 9 (1), 40-45.

[16] Lumenta, J. 2015. Evaluasi Penyimpanan dan Distribusi Obat Psikotropika di Rumah Sakit Jiwa Prof. DR. V.L. Ratumbuysang Manado. Jurnal Ilmiah Farmasi 4(4) 